\title{
Exploring university students' use of technologies beyond the formal learning context: A tale of two online platforms
}

\author{
Liping Deng \\ Department of Education Studies, Hong Kong Baptist University
}

\author{
Nicole Judith Tavares \\ Faculty of Education, The University of Hong Kong
}

\begin{abstract}
Situated within an informal learning context, this study examines how a group of preservice teachers in Hong Kong use Facebook and Google Sites on their own initiative to fulfil their academic and socio-emotional needs during their teaching practice. Also included in the study are the motivating and inhibiting factors that influence student online participation. Guided by an informal learning model and the literature relating to online participation and sense of community, this exploratory study generates its findings from questionnaires, individual interviews and online postings. The results show that the Google Sites created an avenue for the students to share a range of self-developed teaching resources and ideas. Facebook is a more interactive platform through which the participants seek peer support, exchange teaching ideas, and engage in discussions on a variety of topics. Structure and control provided by Google Sites and immediacy and interactivity afforded by Facebook become complementary to each other.
\end{abstract}

\section{Introduction}

With the rise of Web 2.0 technologies that foreground user participation and collaboration (McLoughlin \& Lee, 2007; Merchant, 2009), they have been increasingly introduced into the educational arena. Meanwhile, students' everyday and social life in a technology-rich and always-on mode is mingling with their academic life. This has given rise to a surge of research interest in the use of various technologies across both formal and informal contexts (e.g., Clark, Logan, Luckin, Mee, \& Oliver, 2009; Vaughan, Nickle, Silovs, \& Zimmer, 2011). However, a lot is yet to be discovered in relation to how students choose and appropriate various technologies on their own initiative for learning purposes beyond formal learning settings.

Adopting a case study approach, the present study examined the experience of a group of student teachers at a Hong Kong university who elect to use two online platforms - Facebook and Google Sites - for peer sharing and support. Specifically, the study seeks to understand the cognitive and socioemotional benefits of the two platforms. Guiding our inquiry are three key questions: (1) How did the student teachers use Facebook and Google Sites on their own initiative for cognitive and socioemotional purposes? (2) How do Facebook and Google Sites interplay? (3) What are the factors that influence student teacher engagement with the online platforms? Through addressing these questions, the study aims to illuminate the process underlying students' uptake of online technologies in informal learning contexts and the motivating and inhibiting factors behind online participation. A closer look into the students' self-initiated use of technologies can also have important implications for employing these technologies for learning purposes across formal and informal environments.

\section{Review of related literature}

The study is grounded in relevant theoretical and empirical work on the themes of informal learning. The following literature review will first present the concepts and a framework of informal learning followed by studies on the application of web-based technologies within both formal and informal learning settings.

\section{Informal learning}

In contrast to formal learning, which is typically classroom-based, highly structured and institutionally sponsored, informal learning is primarily directed and regulated by learners themselves (Dabbagh \& Kitsantas, 2012; Marsick \& Watkins, 2001). Informal learning is "undertaken on one's own, either individually or collectively, without either externally imposed criteria or the presence of an 
institutionally authorized instructor" (Livingstone, 2000, p. 2). Such learning happens outside the curricula provided by educational institutions and programs (Schugurensky, 2000) in a highly personalised manner based on students' specified needs, interests and experiences (Bull et al., 2008). Mocker and Spear (1982) attempted to classify formal and informal learning experiences along a continuum of control over learning objectives (what to learn) and learning processes (how to learn).

Viewing this from the socio-cultural lens, learning includes both cognitive and socio-emotional dimensions. Often, educators and researchers tend to focus on cognitive aspects tied to learning tasks and learning outcomes, thereby undermining the importance of the socio-emotional dimension of "getting to know each other, committing to social relationships, developing trust and belonging, and building a sense of on-line community” (Kreijns, Kirschner, \& Jochems, 2003, p. 342). Kreijns, Kirschner, and Vermeulen (2013) further developed a quadrant framework for computer-assisted learning that takes into account more precisely defined cognitive-socio-emotional and task-non-task dimensions. This framework is adapted in the current study (see Figure 1) with quadrant A referring to cognitive processes in a formal learning context, quadrant B depicting socio-emotional processes in a formal learning context, quadrant $\mathrm{C}$ capturing cognitive processes in informal learning contexts, and quadrant D covering socio-emotional processes in informal learning contexts. For example, a required participation in an online discussion forum on course-related topics should be a typical scenario in quadrant $\mathrm{A}$; an online cafe set up by instructors where students can share informally on any topics they are interested in should fall into quadrant B; a Facebook group initiated by students for group collaboration should be assigned to quadrant C; and a Facebook group created by students for socialising and networking falls into quadrant D. This framework provides a useful point of reference for the investigation and interpretation of our findings.

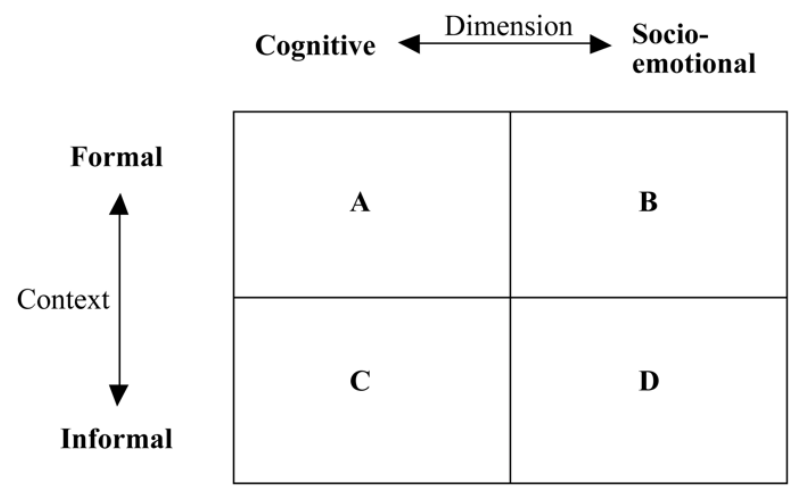

Figure 1. Dimensions of formal and informal learning

\section{Web 2.0 technologies for formal learning}

Web 2.0 technologies have become a powerful impetus for online participation and interactivity (Crook, 2008). The defining characteristics of Web 2.0 tools - participation, connectivity and sharing (Alexander, 2006; McLoughlin \& Lee, 2007; Merchant, 2009) - are deemed to be a good match with personalised and collaborative forms of learning. The past few years have witnessed a fast growing body of research on designing and applying networked social media for diverse pedagogical purposes in formal learning contexts (quadrant $\mathrm{A}$ in Figure 1). As flexible and versatile tools, Web 2.0 technologies such as blogs and wikis can be appropriated to a wide variety of pedagogical needs (Brownstein \& Klein, 2006; Ma \& Yuen, 2008). For example, blogs have been reported to foster selfexpression and self-reflection on the part of students (e.g., Wopereis, Sloep, \& Poortman, 2010), and promote networking, communication and collaborative learning (e.g., Deng \& Yuen, 2011). Wikis, with their shared authorship and open editing mechanism, have a pedagogical role in supporting peer evaluation (Aharony, 2009) and collaborative learning (Dymoke \& Hughes, 2009; Larusson \& Alterman, 2009).

However, much less attention has been given to socio-emotional processes (quadrant B in Figure 1) than to cognitive processes (quadrant A) in formal learning contexts. Researchers have only recently 
begun to explore the affordances of Web 2.0 technologies in this respect. For instance, blogs with their individual ownership and interactive capacities are acclaimed to be conducive to emotional expressions (Deng \& Yuen, 2011). Blogging in a social setting allows students to socialise, support one another and reduce feelings of isolation (Dickey, 2004). Facebook, as a popular social networking website, can contribute to social capital (Ellison, Steinfield, \& Lampe, 2007), enhance peer support and group cohesiveness (English \& Duncan-Howell, 2008), heighten students' self-esteem and strengthen social relationships (Yu, Tian, Vogel, \& Kwok, 2010).

\section{Web 2.0 technologies for informal learning}

Social software has become an integral part of the daily life of young people (Crook, 2008; Selwyn \& Grant, 2009). (It is worth noting that most studies concerning Web 2.0 technologies were conducted in wealthy industrial nations. Thus the easy accessibility to, readiness to use and skills in these technologies by young people should not be viewed as a universal phenomenon.) The proliferation of social software, coupled with increasingly ubiquitous access, has enabled users to easily create and share content and be connected and collaborate with one another; therefore presenting enhanced opportunities for informal learning outside classroom walls (Goodwin, Kennedy, \& Vetere, 2010; Lucas \& Moreira, 2009). Web 2.0 technologies are nevertheless regarded as "disruptive" as they challenge the divide between one's social life and formal learning experience (Jones, Blackey, Fitzgibbon, \& Chew, 2010). There has thus been a growing interest in understanding how informal learning can be enacted by technologies, which may "shed new light on how we learn in the first place" (Sefton-Green, 2004, p. 14).

Several studies in recent years have probed into students' engagement with various Web 2.0 technologies across formal and informal learning contexts. Through a literature review of informal learning with technologies, Sefton-Green (2004) concluded that students' engagement with technologies outside school was a complex educational experience that could complement and supplement learning inside school. Clark et al. (2009) found that teenagers in the United Kingdom used Web 2.0 tools predominantly for social, leisure or entertainment purposes and lacked knowledge of how to deploy the tools to support their own learning (Clark et al., 2009). There were discrepancies recorded between students' use of technologies in and out of school, yet the boundary between formal and informal settings was said to be less clear. Vaughan et al. (2011) explored undergraduates' use of Web 2.0 technologies in supporting group work outside class. Findings of their study in Canada showed that Web 2.0 technologies were used primarily for communication and the sharing of files, while tools such as blogs and wikis were seldom deployed.

A large-scale study conducted by Conole, de Laat, Dillon, and Darby (2008) noted that students across a broad range of disciplines in universities in the United Kingdom were comfortable with technologies and saw them as a crucial part of their learning. They were found using technologies extensively to meet individual needs and to communicate with their peers and tutors. Another study of a similar scale carried out by Smith and Caruso (2010) in North America investigated undergraduates' experience with technology inside and outside the classroom. This study indicated that these students were more engaged in social networking sites (SNSs) than their predecessors and were progressively integrating SNSs and other web-based tools into their learning experiences.

On account of the prevalent role of SNSs in students' daily and social life, there has been increasing research attention on the use of such platforms for informal learning. Vivian (2011) explored Australian university students' motivation for using Facebook for informal learning as well as the perceived benefits and associated problems. Facebook was depicted as a useful, familiar, accessible platform that afforded peer sharing, networking and discussion through a range of applications (e.g., private messages, Instant Chat). Although negative effects of Facebook such as procrastination and distraction were reported, the students still acknowledged Facebook as a valuable platform for informal learning. Fewkes and McCabe (2012) sought to evaluate the use of Facebook among high school students in Canada and reported that its primary function was social. While the majority of students acknowledged that they used Facebook for educational purposes, this was ranked the lowest of all uses for the platform. Findings were similar in another study conducted by Madge, Meek, Wellens, and Hooley (2009) among first-year university students in the United Kingdom: the social functions of Facebook took precedence over its educational functions, and the students were not keen on using it in formal learning settings. 
Despite the prevalence of Web 2.0 tools among students, some scholars have warned against the assumption that all students are technology-savvy and that their engagement with technology in their daily life can be transferred easily to a learning context. Indeed, students' digital competency and engagement show a huge variation across age, gender and socio-economic status (Bennett \& Maton, 2010; Kennedy et al., 2009). There still exists a "participation gap” among young people in terms of access to technology, but more importantly, in participation in social and cultural practices in the technological world (Jenkins, 2009). Additionally, Palaigeorgiou, Triantafyllakos, and Tsinakos (2011) maintained that students were inclined to keep their personal and learning cyberspace experiences apart. Such a divide of social software usage for learning purposes and for personal or social life is termed "socio-learning divide" (Jones et al., 2010).

\section{Research gap}

There is clearly a dearth of studies on how college and university students use various kinds of technologies to support learning on their own initiative and beyond formal classroom settings (Attwell, 2007; Lai \& Gu, 2011; Vaughan et al., 2011). To date, however, most studies on the use of technologies in informal learning contexts take a general view of what and how digital technologies are used. Few studies place emphasis on specific tools used intentionally for learning purposes and how different tools are combined and interplayed. This study sets out to explore how university students in Hong Kong use technologies without intentional pedagogical design or teacher presence (quadrants C and D in Figure 1). In particular, two online platforms that the undergraduates chose to use - Google Sites and Facebook - were examined to determine how these two platforms met their cognitive and socio-emotional needs and to what extent.

\section{Methods}

\section{Background}

The participants of the study are a cohort of student teachers in their early 20s in an English educational program in a Hong Kong comprehensive university. They were in two groups, out of which 42 students (30 from group 1, 12 from group 2) agreed to take part in the study. For one group, the second author was responsible for a year-long core module that included an 8-week teaching practice (TP) when the student teachers were placed in different schools across the territory for internship. The module website was set up on Moodle, a course management system (CMS) hosted by the faculty, and voluntary online discussion was encouraged among them to complement in-class teaching. The instructor herself also acted as an active facilitator in online discussions. In order to keep the student teachers connected, promote group cohesiveness and foster a sharing culture, the instructor created a forum specifically for TP and urged them to use it. Surprisingly, there was no activity in this forum at all during TP. Instead, the instructor received an invitation to visit a website called "TP No Worries" (TPNW) which was created, developed and maintained by the student teachers themselves! It was also found that they used a Facebook group to support peer communication and sharing.

\section{Data collection}

The study employed an exploratory research design and drew on data from questionnaires, interviews and online artifacts. The purpose of the questionnaire was to capture an overall picture of the student teachers' online behavior and their perceptions of and attitudes towards web-based technologies. The questionnaire items were developed based on the researchers' previous work on online participation and Rovai's (2002) instrument for measuring sense of community. The first section of the questionnaire tapped into the student teachers' general computer skills and comfort level with technology. The second section invited them to declare their online behavior, such as their frequency of reading online posts. The third consisted of Likert-type questions that evaluated their perceptions and, in particular, their perceived usefulness of the websites and sense of community (adapted from Rovai, 2002). The questionnaire was distributed to the student teachers at the end of the course and all 42 completed it. Permission to conduct the study was granted by the committee on the use of human and animal subjects in teaching and research prior to the data collection. 
In addition, individual interviews lasting between 30 and 80 minutes were administered with students who either volunteered to take part or were identified through snowballing techniques (Patton, 1990). Altogether 14 students (6 male and 8 female) were interviewed. An attempt was made to include student teachers with varying levels of online engagement; hence, the interviewees were asked to recommend others who fell into certain profiles such as those who were active on Facebook or inactive on TPNW. Among the interviewees was Peter (pseudonym), the student-creator of TPNW. An in-depth interview was conducted with Peter in a bid to understand the process of the website development and its evolvement. An interview protocol was developed consisting of general questions on the student teachers' online experiences and tailor-made questions based on individuals' online activities. Specifically, the interviewees were prompted to reflect on and compare their experiences with and perceptions of TPNW, Facebook and Moodle, and to give concrete examples of their typical activities on each of these platforms. The interviews were transcribed verbatim and coded using NVivo 10 by the two researchers, who performed the coding separately, then cross-examined and discussed the coding schemes together until agreement was reached. Data analysis began with open coding followed by several rounds of recoding and categorisation that involved constant comparison within categories and between categories (Strauss \& Corbin, 1998).

Information was gathered about the student teachers' activities on Moodle and TPNW, as well as the content of online posts, in order to provide an overview of their online engagement and allow for the triangulation of the self-reported data collected through questionnaires and interviews. Since the Facebook group was a closed group, the researchers were not granted access to it. However, the owner of the group assisted in providing some typical examples of the activities in which group members were engaged. Based on the interview data, several usages of Facebook were identified including socialising, exchanging teaching ideas, seeking help, discussing topics related to teaching and peer support. For each category, the owner selected a discussion thread to exemplify the interaction that took place on Facebook.

\section{Results}

\section{Descriptive data of online activities}

As part of the course, the instructor set up a website on Moodle, not only for sharing course materials but also for extending discussions among students and with her outside classes. Altogether 10 such forums were created but overall participation was quite limited. Throughout the course, there were a total of 15 posts and 25 comments made in the forums. There were four forums that had no posts, including the one for TP. The students were invited to report on their frequency of reading the content on Moodle on a scale of 5 - ranging from never to always - via the questionnaire. Among 42 respondents, 8 students (19\%) rated their reading activity as being often or always, 23 (55\%) sometimes and $11(26 \%)$ rarely or almost never $(M=2.95)$. While discussing the hurdles for participating in online discussions on Moodle during the individual interviews, the students shared their views of Moodle as a "formal" and "academic" platform. There was a common perception among many interviewees that Moodle was only a place for them to "download things", not an avenue for "uploading”, to "share thoughts", and to communicate with their peers.

During TP, the instructor discovered through Peter's invitation that he had developed a website called TPNW on Google Sites. TPNW was created with a clear goal in mind: to serve as a central platform for the sharing of teaching resources and ideas during TP. TPNW was set up as a publicly accessible space, yet the right to post and leave comments was only granted to members of the website. Through the questionnaire, the students indicated their frequency of reading the postings on the TPNW website: 9 (21\%) claimed that they never accessed the site, 13 (31\%) rated their participation as rarely or almost never, $15(36 \%)$ sometimes and $5(12 \%)$ often $(M=2.05)$. On top of the home page of TPNW, 12 pages were created and organised under two main categories: Teaching materials and Other reference. The Teaching materials section contained 8 pages designated for specific teaching skills such as speaking, writing and reading. On each page, the students frequently posted messages with a detailed description of the design of the lessons, and uploaded self-developed teaching materials like PowerPoint files, worksheets and lesson plans. The number of posts, attachments and comments listed on each page is presented in Table 1 below. The Other reference category comprised four pages that consisted of references including bookmarks, video links and useful templates such as evaluation forms. 
Table 1

Online content on TPNW

\begin{tabular}{lccc}
\hline Page & Posts & Attachments & Comments \\
\hline Page 1 & 2 & 4 & 4 \\
Page 2 & 1 & 1 & 0 \\
Page 3 & 9 & 30 & 8 \\
Page 4 & 1 & 3 & 0 \\
Page 5 & 5 & 14 & 6 \\
Page 6 & 6 & 17 & 4 \\
Page 7 & 7 & 14 & 4 \\
Page 8 & 5 & 8 & 4 \\
\hline
\end{tabular}

During TP, 13 students posted 36 times in total on TPNW and shared their teaching materials including lesson plans, worksheets, audio and video files there. The most active participant, Peter, had 13 posts and the second most enthusiastic contributor, 9. There were also 10 students who posted a sum of 30 comments on TPNW with an average number of 0.83 comments for each post. Peter again made most comments (11), which accounted for $37 \%$ of all comments. The second most active commenter posted 8 times. It is thus worth noting Peter's leadership role: he not only created and managed the TPNW website but also became the most active contributor of posts and comments.

In the questionnaire, the students also reported the frequency of visiting their Facebook group. Of the students, 16 (38\%) rated their participation on Facebook as always, 13 (31\%) often, 10 (24\%) sometimes and $3(7 \%)$ rarely or never $(M=3.9)$. On average, they visited Facebook more frequently than they did Moodle and TPNW. However, since the researchers were not granted the right to access their Facebook group, their online activities there could not be systematically recorded and analysed. Instead, the researchers were provided with seven examples of the interaction characteristic of the group. Among the seven threads, the highest number of comments received was 41 and the lowest 7 . On average, each post attracted 18 comments, which is a much higher number than that on Moodle and TPNW.

\section{Benefits of TPNW}

Table 2 shows the questionnaire results regarding students' perceptions of the usefulness of TPNW. The responses from 33 TPNW users were mostly positive. Over $85 \%$ of the students agreed to the statement that TPNW fostered an exchange of teaching ideas (24\% strongly agreed, 64\% agreed), with less agreement on the sharing of teaching resources (39\% strongly agreed, 49\% agreed), and getting peer support (21\% strongly agreed, 64\% agreed). Of the students, $79 \%$ also felt that the platform encouraged communication among them (15\% strongly agreed, 64\% agreed). Furthermore, 58\% believed that TPNW stimulated them to reflect on their own teaching (9\% strongly agreed, 49\% agreed). The responses were split on whether TPNW helped to keep peers connected: about half of the students reported agreement (18\% strongly agreed, 33\% agreed), with the other half (42\%) neutral or disagreeing (3\% disagreed, 3\% strongly disagreed).

Table 2

Perceived usefulness of the TPNW website

\begin{tabular}{lllllll}
\hline & SA & A & N & D & SD & Mean \\
\hline Exchange teaching ideas & $8(24 \%)$ & $21(64 \%)$ & $3(9 \%)$ & 0 & $1(3 \%)$ & 4.06 \\
Share teaching resources & $13(39 \%)$ & $16(49 \%)$ & $3(9 \%)$ & $1(3 \%)$ & 0 & 4.24 \\
Keep students connected & $6(18 \%)$ & $11(33 \%)$ & $14(42 \%)$ & $1(3 \%)$ & $1(3 \%)$ & 3.61 \\
Get peer support & $7(21 \%)$ & $21(64 \%)$ & $4(12 \%)$ & $1(3 \%)$ & 0 & 4.03 \\
Reflect on teaching & $3(9 \%)$ & $16(49 \%)$ & $10(30 \%)$ & $3(9 \%)$ & $1(3 \%)$ & 3.52 \\
Support peer communication & $5(15 \%)$ & $21(64 \%)$ & $4(12 \%)$ & $1(3 \%)$ & $2(6 \%)$ & 3.79 \\
\hline
\end{tabular}


During the interviews, it was clear from the students' voices that TPNW was an "uploading and downloading platform” for "materials sharing”. They generally acknowledged the value of TPNW as an avenue for sharing resources among themselves. One student indicated their inclination to post their materials there once finished. Several students exclaimed that there was a pressing need for such a sharing platform during TP since "sometimes you [they] get really stuck and you [they] are so in lack of ideas". Through viewing and using the teaching materials created by their peers, they recognised its benefits in "broaden[ing] my [their] mind", "gain[ing] some inspirations" and "sav[ing] more time on preparation". They also noted that they sometimes downloaded materials such as worksheets for use in their own classes and then shared with the owner of the materials how the ideas worked for them.

To determine the extent to which their online engagement was related to socio-emotional aspects of learning, the relationship between students' online participation, their perceptions and their perceived sense of community were investigated through running the Pearson correlation on the questionnaire responses. The sense of community (SOC) score was obtained by computing the mean value of the four items that aimed at gauging students' sense of belonging to the community. The results suggest that SOC is significantly correlated with their frequency of reading TPNW $(r=.462, p<.01)$ and accessing the Facebook group $(r=.428, p<.01)$. In contrast, no correlation was found between SOC and the students' frequency of reading their course website on Moodle $(r=-0.06, p>.05)$. There was a strong correlation between SOC and the perceived usefulness of TPNW. Notably, SOC correlated significantly with the perceived value of TPNW for exchanging ideas $(r=.612, p<.001)$ and sharing teaching resources $(r=.667, p<.001)$.

\section{Interplay between TPNW and Facebook}

As a website conceived, set up and maintained by the students themselves, TPNW had the strength of being "organized" from their point of view. The uploaded materials were "categorized into different groups and thus easy to follow and to be shared". As one student put it, "we can find the information we want quite easily". However, the platform was also perceived to have its drawbacks. One interviewee recalled how he felt when posting on TPNW: "You don't know when you'll get a reply; you don't know how many people actually looked at your post." Another student commented that TPNW was "good for sharing” but "not good for discussion”.

Yet on Facebook, “you (they) are pretty sure everyone will be looking at it” since it has "already [been] integrated in our [their] daily activities" and become "a part of our [their] lives". One student also noted: "we spend a lot of our time on this popular social networking website. We will get the notification immediately whenever people post." Thus, whenever questions were posted, "immediate responses" could be anticipated. Furthermore, the students believed that the interface of Facebook was more conducive to interactions as "you have the comment box right next to the post." For this reason, Facebook was described as a more "interactive" space, and "the most convenient way for rapid exchange of ideas and information”. Many preferred "asking questions on Facebook". As such, some students felt that Facebook gave them "a greater sense of belonging than 'TP No Worries' because not many of them use ‘TP No Worries' frequently”.

During the interviews, the students listed a wide spectrum of activities in their Facebook group including socialising, seeking help and support, discussing grammar items and exchanging teaching ideas. The following selected scenario of communication in their Facebook group portrays a vivid picture of the affordance of Facebook for interactivity and immediacy. The original post reads:

My next lesson starts in 30 mins! Help! No preparation at all! I am gonna teach the "Salad is easy to make" pattern. "Subject + to be + adj. + to inf."

I have a set of boring worksheets at hand. What can I do to attract Ss' attention and teach them in a less boring way?

One minute later, this student received his first response, and the post eventually attracted 17 comments from 7 different course mates. Later in the same comments thread, the student shared his teaching experience and mentioned that he was going to post the PowerPoint file of the lesson on the TPNW website, which points to the complementary nature of the two online platforms (to be discussed in a later part of this paper). In another example, a student wrote: "my students said i can use less ppt, could you please share your lesson that goes along this direction?” The first comment was posted 5 
minutes later, and 6 other postings ensued over the next 12 minutes, in which peers shared their personal experiences and perspectives.

However, students realised that Facebook has an inherent problem: "it is not so organised... and we can't find the information easily”. According to them, another aspect that gave TPNW an edge over Facebook was that "you can control the structure, like you are designing your own webpage”, while "Facebook doesn't allow that kind of flexibility". One student even complained that "the problem with Facebook is, it's always changing... It is a bit annoying”. By contrast, as a self-maintained website, TPNW was "stable in terms of its structure".

Further to the complementary functions of the two platforms mentioned above, during the interviews the students expressed their perceptions of the distinctive roles of TPNW and Facebook, as per the following examples:

We know where to post and we have a very very clear idea about the purpose of why we use these different things [technologies]

If I use ‘TP No Worries’, I post things up, then I chat with others on Facebook

One [Facebook] allows for an instant and interactive discussion, another [TPNW] is for uploading and sharing materials

The students were generally comfortable with the co-existence of the two platforms, seeing them as being "connected" and using them in viable ways for themselves and in sharing information with their peers.

There were in fact many references to the interplay between the two platforms in the interview data. To cite but some further examples, a student shared a teaching idea in their Facebook group, received a request from her peers to share the lesson plan, then uploaded the materials on TPNW followed by a notification message on Facebook with a link to the relevant TPNW page. Another student downloaded a lesson plan from TPNW, but upon encountering problems using it, turned to the Facebook group for clarification and help. Among the sampled interactions collected from the Facebook group, there was one announcing the operation of the new website TPNW. The creator, Peter, posted the link to TPNW on Facebook, inviting his peers to visit the site and become members.

\section{Technologies for formal learning contexts}

When the students were asked whether they would welcome their instructors' presence on TPNW, most gave an affirmative response. As one student remarked, "they can comment on our ideas and give us suggestions or they can post new questions which can trigger our thoughts and discussions”. In spite of this, a few students frankly expressed their reservations on the basis of a sense that the instructor's visibility might deter them from sharing their "not-so-perfect" materials and lesson plans on TPNW. They were of the impression that the instructors would inevitably judge their performance from their postings. In a similar vein, the students were positive about using Facebook in formal learning settings. Many liked the idea and listed the advantages of Facebook over Moodle, among which were their familiarity with the interface and functionalities of the former. However, serious concerns were raised over privacy issues, such as whether their instructors could "gain access to my profile page”.

Despite the good relationship between the instructor and these students, there was strong resistance to having her as a member of their Facebook group, with some students commenting that it was "inappropriate", "uncomfortable", and "a little bit scary". They conveyed a powerful and unanimous message that their Facebook group was their "own place” where they could "talk about anything freely". They worried that the presence of an instructor would jeopardise the atmosphere of free sharing and discussion about "anything". One student even remarked candidly and directly that "this is just a norm for students’ groups; you usually will not invite the tutors”.

\section{Motivation for online participation}

The interviews offered a rich set of data on the students' perceptions of TPNW for peer sharing. Out of the 14 students interviewed, 12 used TPNW. On probing into their motivation to post their materials online, they highlighted two most salient driving forces: peer recognition for their efforts and 
confidence. As one student pointed out, "When other classmates used my materials and they told me that it's useful, ... it helps me to get more confidence.” To them, a great sense of satisfaction was derived from being told that their ideas or plans were adopted or adapted in others' classrooms. When they received peer feedback on how to improve, it also helped them "reflect on my [their] lesson plans" and "learn something new". The creator of TPNW, Peter, shared a similar view:

The reasons for me to post my materials on Google Sites [TPNW] is not only to share them with my classmates but also to listen to their comments as well, to see how they actually use it [the materials] in their classroom.

Many students simply enjoyed the process of sharing, stressing that "it's always good to share". One student mentioned: "We really spend a lot of time preparing for our teaching practice so why don't we share our materials?" especially since "there are chances that we will... teach the same topic or the same grammar items”.

Linked to the above is another motivating force, a sense of community, encapsulated by a simple comment from one of the students: "I tried to help a little bit because this is a community". Online participation, in turn, can generate an even greater sense of belonging, as is reflected in this comment: "When you participate, you will feel like you are a part of it". Others shared their materials, taking the lead from other course mates. One student emphasised that her participation was heavily influenced by Peter who, in her words, was "a great teacher"; thus, she wanted to "join hands with him" and not "let him down”.

\section{Barriers for online participation}

However, there were several students who openly admitted their lack of interest in either visiting TPNW or downloading materials from it. One was unable to find suitable teaching materials after browsing TPNW, claiming that there was "not enough information and it takes time". Another expressed her reservations about "borrowing” others' materials directly, adding that "after all, you need to cater for your learners' needs”. A third student who did not often log in to TPNW felt that the shared materials were "very contextualized", thus rendering modification a time-consuming process. A further impediment to using TPNW was that it was only publicised through Facebook, which less avid users of Facebook might have missed. Indeed, one student surprisingly mentioned at the interview that she was not aware of the existence of TPNW until the end of TP, since she had overlooked the first announcement on Facebook.

Time constraint was identified as a daunting challenge during TP. Even Peter asserted that "[w]hen you get busy, it is very difficult to share." It is apparent that "workload" had a negative impact on the students' online activities. Another reason given for students not sharing materials was that "they didn't know if others would need them.” One student disclosed his lack of confidence when interviewed, stating that he was "not so good at teaching”, thus explaining his hesitation to post his materials on TPNW (although he shared them with several close friends through other means).

The few peer comments on TPNW were also perceived as a factor that discouraged participation. A student who uploaded some lesson plans at the beginning of TP recollected his disappointment: "I had to type everything out and make the instructions very clear. But I had no feedback from my peers. So I asked myself, 'Did anyone really look at that? Is it worthwhile uploading something?'” The two most active contributors on TPNW also highlighted the power of peer feedback. Peter expounded, "if no one responds, you don't know whether others find it useful or not. This just demotivates you to do it." Another course mate echoed his views: "Our classmates are not very participative, so it kind of demotivated us to continue”. It is thus evident that those who shared their materials online expected feedback from their peers and considered such response as recognition of their effort.

Interaction and dialogic feedback was nevertheless limited on TPNW. When the students were asked why they were reluctant to comment on their peers' work, lack of time was again named as a prime reason. Another interesting point made was that the close relationship among students became a conflicting force for their sharing of ideas: "I think commenting is very good. But when you are so close to each other sometimes it is quite difficult to comment... It's quite embarrassing to tell her what kind of improvements to make.” Some students also noted a degree of uncertainty over the 
appropriateness of criticising others' work published online: "Maybe not all of us would think it's right to comment on others' products”. Another leading reason for the lack of interaction on TPNW was that communication was not confined to one channel; the students dialogued with one another via different means, predominantly through Facebook, with the instant messaging system WhatsApp and telephone conversations being other common methods.

A final factor to be taken into consideration was that there were storage limits (100MB), file limits (20MB) and other constraints to using Google Sites as the platform for TPNW. Since the students uploaded large volumes of material, including Word, PowerPoint and audio files, space became an issue. In the middle of TP the uploaded materials exceeded the limit, as one student noted his experience: "After a certain period we tried to upload things but it [Google Sites] stopped us from uploading. So we stopped working on that platform.” Another less favorable feature of the platform was identified as follows: “sometimes when people comment on your materials, you don't get notifications, so I [the student] missed the feedback until really late."

\section{Discussion}

The students who participated in the present study showed little interest in taking part in an institutionalised Moodle for peer sharing despite the instructor's constant encouragement and her role as facilitator in the online discussion. As CMSs are centrally controlled and managed by the teaching staff who define the learning objectives, tasks and tools to be used (Väljataga, Pata, \& Tammets, 2011), they are normally classified within the domain of formal learning contexts (see quadrant A in Figure 2). Interestingly, however, the students reported a higher frequency of accessing the course website on Moodle than on the TPNW website. One plausible explanation is that there was a necessity to make reference to the materials posted on Moodle throughout the course. This relatively higher attendance rate on Moodle nevertheless is not associated with the students' sense of community. Overall, there was a widespread feeling among them that Moodle was a one-way system serving academic purposes only. This perception might be based on their past experience with CMSs. The students mentioned that in spite of the fact that almost all the courses used CMSs, very few instructors utilised the feature of online discussion (see Deng \& Tavares (2013) for more comparison of Moodle and Facebook). The perception of Moodle as a predominantly cognitive device might serve to explain its underuse as an interactive platform for peer sharing and socialisation. In fact, many studies have reported such problem (see Brown \& Adler, 2008; Hamuy \& Galaz, 2010; Lonn \& Teasley, 2009).

TPNW, on the other hand, was conceptualised, developed and maintained by the students. It was a grassroots initiative emerging from the students' genuine needs for connecting with, sharing with and supporting one another during their TP. Hence, TPNW falls into the category of an informal learning (quadrant $\mathrm{C}$ in Figure 2), since learning control and management are in the hands of the learners (Livingstone, 2000). The TPNW website was shown to support self-directed learning that was intentionally planned and valued by the students themselves (see Schugurensky, 2000). It was set up as a publicly accessible website and the instructor was invited to visit it. Underlying the students' selfinitiated use of technologies for informal learning is a strong sense of ownership and learner control. This suggests that web-based technologies have the potential to offer a remedy for addressing the problem of learner control and personalisation often absent in institution-developed CMSs (Dabbagh \& Kitsantas, 2012).

First and foremost, the findings of this study indicate that the students are ready for and capable of using web-based technologies to fulfill their learning and socio-emotional needs. Those who used TPNW attached very positive values to it for exchanging teaching ideas, sharing teaching materials created on their own and supporting fellow students during their TP. Even though they reported a lower frequency of reading the postings on TPNW as compared to those on the course Moodle website, this frequency is correlated with their felt sense of community. That is to say, TPNW not only met their cognitive needs but also contributed to their socio-emotional well-being (see quadrants C and D in Figure 2).

Secondly, the students in the study actively engaged in their Facebook group. They demonstrated a sound understanding of the different affordances of TPNW and Facebook and regarded the two as complementary: TPNW for the exchange of resources and sharing of teaching ideas; Facebook for communication, discussion and sharing on a variety of topics. They deployed the two online platforms 
for addressing different needs, moving between them with apparent ease. TPNW was a more organised place to store, share and search for teaching materials, but a less favorable environment for peer interaction. Thus, instead of pursuing discussions on TPNW, they reverted to their Facebook group for socialising, seeking help and exchanging ideas due to the strong sense of immediacy and convenience facilitated by this online platform. In this sense, Facebook is better positioned as an interactive ground affording socio-emotional needs. The findings here are therefore in line with several previous studies that collectively acclaim student use of Facebook for affective communication (English \& DuncanHowell, 2008).

Figure 2 shows the roles of technological platforms under study. Moodle resided in formal learning dimension serving mostly for cognitive needs of the students. TPNW and Facebook worked together in catering for both the cognitive and socio-emotional needs of the students. TPNW rests more heavily on the cognitive side, with the affordances for the socio-emotional domain being secondary. From the data gathered, it is inconclusive as to whether Facebook functions better as a cognitive or socio-emotional orientated platform.

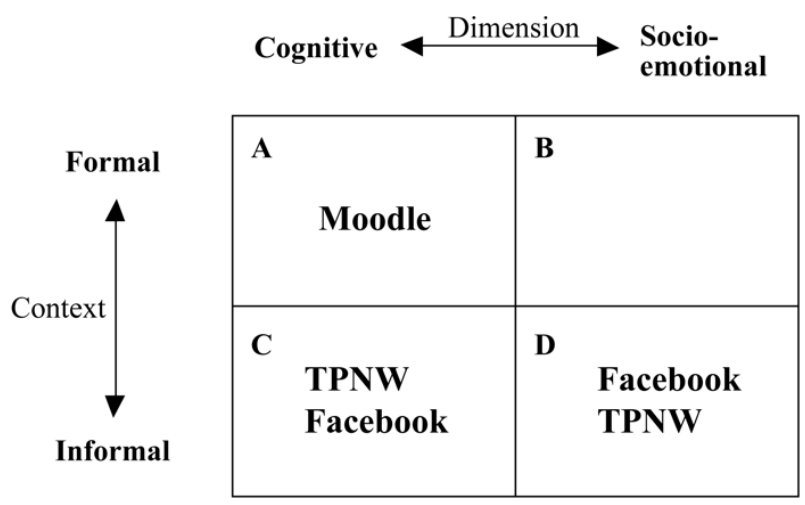

Figure 2. Roles of TPNW and Facebook

The motivating and inhibiting factors for students' engagement with TPNW were also investigated. Resonant of Deng and Yuen (2012), our study revealed that the students' online participation was influenced by a set of individual, social and academic elements. Some students considered online sharing intrinsically rewarding as it enabled the contributors to gain recognition for their effort and hence boosted their confidence. Others were stimulated and inspired by the creator of TPNW and the felt sense of belonging to their peer group. The students considered the sharing of self-developed materials online beneficial for their fellows who can simply download and use at their will, as well as a good learning experience for contributors when they receive peer feedback, especially when their materials were adapted and tried out in other classroom contexts.

Our study also identified inhibiting factors that impact on students' online engagement as both consumers and producers. Time constraint was regarded as a major barrier, with lack of appreciation of the website as a valuable platform also deterring student participation. In addition, for some students, uncertainty over the usefulness and quality of their work posed a psychological hurdle to sharing their teaching materials on the web. Although the social environment favored student engagement, it also had a negative effect, in that the close relationship among the students was reported to hinder their evaluation of and thus commenting on others' work. Last but not least, the limited storage of the commercial online platform restricted uploading beyond a certain point, and hence, sharing.

\section{Conclusion}

Focusing on the two online platforms TPNW and Facebook, this study explores in depth the affordances of web-based technologies in both cognitive and socio-emotional dimensions. Findings of the study have some implications for both researchers and practitioners. Firstly, if emphasis is laid 
solely on the technologies used within a formal learning context as with CMSs like Moodle, only limited engagement with the technologies is discerned. However, when investigations are extended beyond this context, a much richer experience and more complex practices with technologies begin to unfold. This points to the significance of taking a more holistic view when examining what goes on inside as well as outside the classroom to capture a more comprehensive and dynamic picture of the use of technologies and their impact on student learning. To this end, the framework of formalinformal learning presented in Figure 1 can serve as a valuable frame of reference. Some areas that warrant further investigation include the following: To what extent does a certain technology serve cognitive and socio-emotional purposes? In informal learning settings, how do cognitive and socioemotional dimensions intersect and interplay? In what way do and should instructors encourage students to create informal online learning spaces, and to what extent do they intervene? Can the socioemotional aspect of a technology inhibit or distract students from learning? An important distinction worth noting is that cognitive/socio-emotional and formal/informal are two ends of a continuum, rather than dichotomous concepts.

Secondly, the study brings to light some challenges for educators using technologies in formal educational settings. As the findings summarised in Figure 2 show, Moodle resides mostly in the formal and cognitive domain. While the instructor had a good relationship with the students in our case, as indicated by her being invited to browse their contributions in TPNW, it was still insufficient to change their unenthusiastic attitude towards Moodle and stimulate their interest in online participation. An underlying challenge for teachers here is how best to utilise technologies to meet the socio-emotional needs of students within a formal context. One suggestion is to utilise those tools for social and informal communication. For example, blogs (see Deng \& Yuen, 2011; Dickey, 2004) and Facebook (see McCarthy, 2013; Yu et al., 2010) can create an avenue conducive to social interaction and peer support.

Thirdly, most of the studies on the use of technologies for informal learning revolve around describing students' activities and behaviors. More research efforts are needed to articulate the guidelines and principles for teachers to harness or integrate technologies in their students' everyday life for their effective use in formal learning contexts. It is hoped that insights gleaned from this study regarding students' perceptions of technologies and the factors influencing their use of technologies might inform further related studies. Indeed, there is still much yet to be understood regarding the transferability of technology-supported learning between formal and informal learning contexts.

\section{Acknowledgements}

This study was funded by a start-up grant from Hong Kong Baptist University. We would like to thank all the participating students for their support of our research.

\section{References}

Aharony, N. (2009). The use of a wiki as an instructional tool: A qualitative investigation. Journal of Web Librarianship, 3(1), 35-53. doi:10.1080/19322900802660334Alexander, B. (2006). Web 2.0: A new wave of innovation for teaching and learning? Educause Review, 41(2), 32-44. Retrieved from http://www.educause.edu/ero

Attwell, G. (2007). Personal learning environments: The future of eLearning? eLearning Papers, 2(1), 1-7. Retrieved from http://www.openeducationeuropa.eu/en/elearning_papers

Bennett, S., \& Maton, K. (2010). Beyond the “digital natives” debate: Towards a more nuanced understanding of students' technology experiences. Journal of Computer Assisted Learning, 26(5), 321-331. Retrieved from http://wileyonlinelibrary.com/journal/jcal

Brown, J. S., \& Adler, R. P. (2008). Minds on fire: Open education, the long tail, and learning 2.0. Educause Review, 43(1), 16-32. Retrieved from http://www.educause.edu/ero

Brownstein, E., \& Klein, R. (2006). Blogs: Applications in science education. Journal of College Science Teaching, 35(6), 18-22. Retrieved from http://www.nsta.org/college/

Bull, G., Thompson, A., Searson, M., Garofalo, J., Park, J., Young, C., \& Lee, J. (2008). Connecting informal and formal learning experiences in the age of participatory media. Contemporary Issues in Technology and Teacher Education, 8(2), 100-107. Retrieved from http://www.citejournal.org/ 
Clark, W., Logan, K., Luckin, R., Mee, A., \& Oliver, M. (2009). Beyond Web 2.0: Mapping the technology landscapes of young learners. Journal of Computer Assisted Learning, 25(1), 56-69. doi:10.1111/j.1365-2729.2008.00305.x

Conole, G., de Laat, M., Dillon, T., \& Darby, J. (2008). “Disruptive technologies”, "pedagogical innovation”: What's new? Findings from an in-depth study of students' use and perception of technology. Computers \& Education, 50(2), 511-524. doi:10.1016/j.compedu.2007.09.009

Crook, C. (2008). Web 2.0 technologies for learning: The current landscape-opportunities, challenges and tensions (Becta Research Report). Retrieved from http://dera.ioe.ac.uk/1474/1/becta_2008_web2_currentlandscape_litrev.pdf

Dabbagh, N., \& Kitsantas, A. (2012). Personal learning environments, social media, and self-regulated learning: A natural formula for connecting formal and informal learning. The Internet and Higher Education, 15(1), 3-8. doi:10.1016/j.iheduc.2011.06.002

Deng, L. \& Tavares, N. (2013). From Moodle to Facebook: Exploring students’ motivation and experiences in online communities. Computers \& Education, 68,167-176. Retrieved from http://www.journals.elsevier.com/computers-and-education/

Deng, L., \& Yuen, H. K. (2011). Towards a framework for educational affordances of blogs. Computers \& Education, 56(2), 441-451. doi:10.1016/j.compedu.2010.09.005

Deng, L., \& Yuen, H. K. (2012). Understanding student perceptions and motivation towards academic blogs: An exploratory study. Australasian Journal of Educational Technology, 28(1), 48-66. Retrieved from http://ascilite.org.au/ajet/submission/index.php/AJET/index

Dickey, M. D. (2004). The impact of web-logs (blogs) on student perceptions of isolation and alienation in a web-based distance-learning environment. Open Learning, 19(3), 279-291. doi:10.1080/0268051042000280138

Dymoke S., \& Hughes J. (2009) Using a poetry wiki: How can the medium support pre-service teachers of English in their professional learning about writing poetry and teaching poetry writing in a digital age? English Teaching: Practice and Critique, 8(3), 91-106.

Ellison, N. B., Steinfield, C., \& Lampe, C. (2007). The benefits of Facebook “friends:” Social capital and college students' use of online social network sites. Journal of Computer-Mediated Communication, 12(4), 1143-1168. doi:10.1111/j.1083-6101.2007.00367.x

English, R. M., \& Duncan-Howell, J. A. (2008). Facebook® goes to college: Using social networking tools to support students undertaking teaching practicum. Journal of Online Learning and Teaching, 4(4), 596-601. Retrieved from http://jolt.merlot.org/

Fewkes, A. M., \& McCabe, M. (2012). Facebook: Learning tool or distraction? Journal of Digital Learning in Teacher Education, 28(3), 92-98. Retrieved from http://www.tandfonline.com/loi/ujdl20\#.VILzjWSUfiI

Goodwin K., Kennedy G., \& Vetere F. (2010) Getting together out-of-class: Using technologies for informal interaction and learning. In C. H. Steel, M. J. Keppell, P. Gerbic, \& S. Housego (Eds.), Curriculum, Technology \& Transformation for an Unknown Future. Proceedings ascilite Sydney 2010 (pp. 387-392). Retrieved from http://ascilite.org.au/conferences/sydney10/procs/Goodwinconcise.pdf

Hamuy, E., \& Galaz, M. (2010). Information versus communication in course management system participation. Computers \& Education, 54(1), 169-177. doi:10.1016/j.compedu.2009.08.001

Jenkins, H. (2009). Confronting the challenges of participatory culture: Media education for the 21st century. Cambridge, MA: MIT Press.

Jones, N., Blackey, H., Fitzgibbon, K., \& Chew, E. (2010). Get out of MySpace! Computers \& Education, 54(3), 776-782. doi:10.1016/j.compedu.2009.07.008

Kennedy, G., Dalgarno, B., Bennett, S., Gray, K., Waycott, J., Judd, T., ... Chang, R. (2009). Educating the net generation: A handbook of findings for practice and policy. Retrieved from http://www.netgen.unimelb.edu.au/downloads/handbook/NetGenHandbookAll.pdf

Kreijns, K., Kirschner, P. A., \& Jochems, W. (2003). Identifying the pitfalls for social interaction in computer-supported collaborative learning environments: A review of the research. Computers in Human Behavior, 19(3), 335-353. doi:10.1016/S0747-5632(02)00057-2

Kreijns, K., Kirschner, P. A., \& Vermeulen, M. (2013). Social aspects of CSCL environments: A research framework. Educational Psychologist, 48(4), 229-242. doi:10.1080/00461520.2012.750225

Lai, C., \& Gu, M. (2011). Self-regulated out-of-class language learning with technology. Computer Assisted Language Learning, 24(4), 317-335. doi: 10.1080/09588221.2011.568417 
Larusson, J. A., \& Alterman, R. (2009). Wikis to support the "collaborative” part of collaborative learning. International Journal of Computer-Supported Collaborative Learning, 4(4), 371-402. doi:10.1007/s11412-009-9076-6

Livingstone D. W. (2000) Exploring the icebergs of adult learning: Findings of the first Canadian survey of informal learning practices. Ontario Institute for Studies in Education.

Lonn, S., \& Teasley S. D. (2009). Saving time or innovating practice: Investigating perceptions and uses of learning management systems. Computers \& Education, 53(3), 686-694. doi:10.1016/j.compedu.2009.04.008

Lucas, M., \& Moreira, A. (2009). Bridging formal and informal learning - A case study on students' perceptions of the use of social networking tools. In U. Cress, V. Dimitrova, \& M. Specht (Eds.), Learning in the synergy of multiple disciplines (pp. 325-337). Berlin: Springer.

Ma, W. W., \& Yuen, A. H. (2008). News writing using wiki: Impacts on learning experience of student journalists. Educational Media International, 45(4), 295-309. doi:10.1080/09523980802571564

Madge, C., Meek, J., Wellens, J., \& Hooley, T. (2009). Facebook, social integration and informal learning at university: "It is more for socialising and talking to friends about work than for actually doing work.” Learning, Media and Technology, 34(2), 141-155. Retrieved from http://www.tandfonline.com/toc/cjem20/current\#.VIL112SUfiI

Marsick, V. J., \& Watkins, K. E. (2001). Informal and incidental learning. New Directions for Adult and Continuing Education, 2001(89), 25-34. doi:10.1002/ace.5

McCarthy, J. (2013). Learning in Facebook: First year tertiary student reflections from 2008 to 2011. Australasian Journal of Educational Technology, 29(3), 337-356. doi:10.1234/ajet.v29i3.373

McLoughlin C., \& Lee M. (2007) Social software and participatory learning: Pedagogical choices with technology affordances in the Web 2.0 era. In ICT: Providing choices for learners and learning. Proceedings ascilite Singapore 2007 (pp. 664-675). Retrieved from http://www.ascilite.org.au/conferences/singapore07/procs/mcloughlin.pdf

Merchant, G. H. (2009). Web 2.0, new literacies, and the idea of learning through participation. English Teaching: Practice and Critique, 8(3), 8-20.

Mocker D. W., \& Spear G. E. (1982). Lifelong learning: Formal, nonformal,informal, and selfdirected. Information Series No. 241. Columbus, OH: ERIC Clearinghouse on Adult, Career, and Vocational Education.

Palaigeorgiou, G., Triantafyllakos, G., \& Tsinakos, A. (2011). What if undergraduate students designed their own web learning environment? Exploring students' web 2.0 mentality through participatory design. Journal of Computer Assisted Learning, 27, 146-159. doi:10.1111/j.13652729.2010.00382.x

Patton M. Q. (1990) Qualitative evaluation and research methods. Newbury Park, CA: Sage Publications.

Rovai, A. P. (2002). Development of an instrument to measure classroom community. The Internet and Higher Education, 5(3), 197-211. doi:10.1016/S1096-7516(02)00102-1

Schugurensky D. (2000). The forms of informal learning: Towards a conceptualization of the field. Toronto: Ontario Institute for Studies in Education of the University of Toronto.

Sefton-Green J. (2004). Literature review in informal learning with technology outside school. Bristol: NESTA Futurelab.

Selwyn, N., \& Grant, L. (2009). Researching the realities of social software use - an introduction. Learning, Media and Technology, 34(2), 79-86. doi:10.1080/17439880902921907

Smith S. D., \& Caruso J. B. (2010). The ECAR study of undergraduate students and information technology, 2010. Washington, DC: EDUCAUSE.

Strauss A., \& Corbin J. (1998). Basics of qualitative research: Techniques and procedures for developing grounded theory (2nd ed.). Thousand Oaks, CA: Sage Publications.

Väljataga, T., Pata, K., \& Tammets, K. (2011). Considering students’ perspectives on personal and distributed learning environments in course design. In M. J. W. Lee \& C. McLoughlin (Eds.), Web 2.0-based E-learning: applying social informatics for tertiary teaching (pp. 85-107). Hershey, PA: Information Science Reference.

Vaughan, N., Nickle, T., Silovs, J., \& Zimmer, J. (2011). Moving to their own beat: Exploring how students use web 2.0 technologies to support group work outside of class time. Journal of Interactive Online Learning, 10(3), 113-127. Retrieved from http://jolt.merlot.org/

Vivian, R. (2011). University students’ informal learning practices using Facebook: help or hindrance? In R. Kwan, C. McNaught, P. F. L. Wang, \& K. C. Li (Eds.), Tsang, Enhancing learning through technology. Education unplugged: Mobile technologies and web 2.0 (Vol. 177, pp. 254-267). Berlin: Springer. 
Wopereis, I. G., Sloep, P. B., \& Poortman, S. H. (2010). Weblogs as instruments for reflection on action in teacher education. Interactive Learning Environments, 18(3), 245-261. doi:10.1080/10494820.2010.500530

Yu, A. Y., Tian, S. W., Vogel, D., \& Kwok, R. C. W. (2010). Can learning be virtually boosted? An investigation of online social networking impacts. Computers \& Education, 55(4), 1494-1503. doi:10.1016/j.compedu.2010.06.015

Corresponding author: Liping Deng, liping@graduate.hku.hk

Australasian Journal of Educational Technology (c) 2015.

Please cite as: Deng, L., \& Tavares, N.J. (2015). Exploring university students' use of technologies beyond the formal learning context: A tale of two online platforms. Australasian Journal of Educational Technology, 31(3), 313-327. 